\title{
O narrador em $O$ evangelho segundo Jesus Cristo, de José Saramago
}

\section{The narrator in The Gospel According to Jesus Christ, by José Saramago}

\section{Diana Almeida Lourenço* $U F P R$}

Resumo: Em O Evangelho Segundo Jesus Cristo, José Saramago se propõe a recontar a história mais arquiconhecida da sociedade ocidental: a vida de Cristo. É criada uma paródia dos Evangelhos canônicos e constrói-se uma crítica não só a Igreja, mas a toda tradição cristã. A paródia religiosa é dos pontos crucias da narrativa, nosso artigo volta-se para análise da figura responsável por conduzir o leitor por essa nova história de Cristo: o narrador. Nosso objetivo é traçar o perfil do narrador de $O$ Evangelho Segundo Jesus Cristo e para isso iremos nos basear nas teorias Gerárd Genette. Também exploraremos suas características baseados em conceitos teóricos como a paródia e ironia, norteados pelos estudos de Linda Hutcheon sobre a paródia moderna.

Palavras-chave: narrador, Saramago, Evangelho.

\begin{abstract}
In The Gospel According to Jesus Christ, José Saramago aims to recount the best known history of society: the life of Christ. It created a parody of the canonical Gospels and a critique is built not only the Church, but the whole Christian tradition. The religious parody is the crucias points of the narrative, our article turns to analysis of the figure responsible for leading the reader through this new story of Christ: the narrator. Our goal is to profile the narrator of The Gospel According to Jesus Christ and for this we will build on the Gérard Genette theories. It will also explore its features based on theoretical concepts such as parody and irony, guided by studies of Linda Hutcheon on modern parody.
\end{abstract}

Keywords: narrator, Saramago, Gospel.

Nosso artigo terá como objetivo à análise e interpretação de uma das instâncias narrativas mais importantes do romance: o narrador. O narrador saramaguiano é diferente com características bem marcantes. Ele seduz o leitor, leva-o em suas reflexões, em suas divagações e em suas viagens pelo tempo, conta o que o leitor ainda não sabe e cobra o que já deveria saber. Referindo-se de um modo íntimo ao receptor, ele conduz a narrativa de tal forma que o leitor percebe que a narrativa, apesar de ser diferente da história dos textos canônicos, é tão interessante quanto.

Além disse, o narrador é uma figura central para a investigação de qualquer obra:

\author{
* Mestranda em \\ Estudos Literários. \\ Orientador: Prof. Dr. \\ Antonio Augusto \\ Nery. E-mail: \\ dianaki@hotmail. \\ com
}


Toda narrativa se estrutura sobre cinco elementos, sem os quais ela não existe. Sem os fatos não há história, e quem vive os fatos são os personagens, num determinado tempo e lugar. Mas para ser prosa de ficção é necessária a presença do narrador, pois é ele fundamentalmente que caracteriza a história. (GANCHO, 1995, p. 9)

O narrador na obra de Saramago assume papel importante para o desenvolvimento da narrativa. É através das impressões, do seu olhar, de seus comentários e maneiras de narrar, que nós, leitores investigadores, somos conduzidos pela história.

Carlos Reis desenvolveu um estudo sobre a narrativa no qual adota as teorias de Gerárd Genette sobre a classificação do narrador que usaremos como referência para análise de OESJC, por parecer mais adequada ao intuito proposto por esse artigo.

Segundo Genette, há uma confusão entre o que ele chama de modo e voz, ou entre as perguntas quem vê? E a pergunta quem fala? Segundo o autor a informação diegética é veiculada pelo narrador através de uma perspectiva, ou seja, de um ponto de vista, ou foco narrativo. Genette explica que a voz do narrador (que é a sua identidade) e o seu ponto de vista (que pode ser interior ou exterior), não são necessariamente a mesma coisa, por isso para classificar um narrador é preciso distinguir esses conceitos:

É sem dúvida legítimo encarar um tipologia das “situações narrativas” que tenha em conta ao mesmo tempo os dados de modo e de voz; o que não é, é apresentar uma classificação dessas sob a categoria única do "ponto de vista”, ou compor uma lista onde as duas determinações se concorrenciam na base de uma manifesta confusão [...] Para evitar aquilo que os termos de visão, de campo e de ponto de vista têm de especificamente visual, retomarei aqui o termo um pouco mais abstrato de focalização. (GENETTE, 1980, p. 186-187, grifos do autor)

A partir dessas ideias, Genette desenvolveu três tipos de focalização do narrador: $1^{\circ}$ narrativa não focalizada, ou de focalização zero; $2^{\circ}$ narrativa de focalização interna, que se subdivide em fixa, variável ou múltipla e $3^{\circ}$ narrativa de focalização externa.

A classificação de Genette, posteriormente passou por estudos de teóricos que muito auxiliaram em sua compreensão. Entre eles Carlos Reis, Jean-Michel Adam e Françoise Revaz que utilizaremos aqui para tornar a divisão mais clara. Sendo assim a classificação do narrador assume essa classificação:

Focalização Onisciente: “O narrador não adota nenhum ponto de vista particular e da ao leitor uma informação completa. Os dois são oniscientes, eles sabem mais do qualquer outro ator da diegese.” (ADAM, 1997, p. 100);

Focalização interna: “condicionada pelo campo da consciência sentido, percepções, apreciações, etc. - de uma personagem inserida na 
história (a percepção é ativada no interior ou do interior da personagem)" (REIS, 1995, p.366);

Focalização externa: “Limitada à superfície do visível e cingindo a informação narrativa ao exterior dos elementos observados (pode resultar também das limitações do olhar de uma personagem)” (GENETTE, 1980, p. 188).

No entanto é fundamental lembrar que uma obra literária pode ter variações na focalização do narrador, ou seja, pode começar com um tipo de focalização e terminar com outra, entre outras possibilidades.

Para Genette, não importa em qual pessoa se narra a história, mas sim a situação narrativa em que essa pessoa se encontra. Ele explica:

[...] não empregamos os termos de "narrativa na primeira - ou na terceira - pessoa” a não ser providos de aspas de protesto. Essas locuções comuns parecem-me, com efeito, inadequadas, pelo colocar do acento da variação sobre o elemento de fato invariante da situação narrativa, a saber, presença, explícita ou implícita, da "pessoa” do narrador que só pode estar na sua narrativa, tal como qualquer sujeito na enunciação no seu enunciado, na "primeira pessoa" [...] A escolha do romancista não é feita entre duas formas gramaticais, mas entre duas atitudes narrativas (de que as formas gramaticais são apenas uma consequência mecânica): fazer contar a história por uma das suas "personagens", ou por um narrador estranho a essa história. A presença de verbos na primeira pessoa num texto narrativo pode, pois, reenviar, para duas situações muito diferentes, que a gramática confunde, mas a análise narrativa deve distinguir: a designação do narrador enquanto tal por si mesmo, [...] e a identidade de pessoa entre o narrador e uma das personagens da história. O termo "narrativa na primeira pessoa", não se refere, muito evidentemente, senão à segunda dessas situações, dissimetria que confirma sua impropriedade. Na medida em que o narrador pode a todo instante intervir como tal, na narrativa, toda narrativa é, por definição, virtualmente feita na primeira pessoa [...]. A verdadeira questão é a de saber se o narrador tem ou não ocasião de empregar a primeira pessoa para designar uma das suas personagens. (GENETTE, 1980, p.242-243)

Nessa citação, Genette explica que a forma gramatical não é o que determina o tipo do narrador, na sua classificação. Um narrador estará sempre em "primeira pessoa", segundo o teórico. O que deve ser analisado é a atitude narrativa dessa "pessoa”. Portanto, quanto aos tipos de situação narrativa o narrador pode ser:

Heterodiegético: "Situação em que o narrador relata uma história a que é estranho, porque a não integra nem integrou como personagem” (REIS, 1995, p. 370);

Homodiegético: “Tendo vivido a história como personagem, o narrador retira dessa experiência as informações que faculta. Entretanto, essa 
relação experiencial refere-se fundamentalmente à vivência da história como personagem secundária ou mera testemunha.” (REIS, 1995, p. 371);

Autodiegético: Quando o narrador viveu a história como protagonista.

Optamos por esses pressupostos teóricos de classificação do narrador, que iremos desenvolver na interpretação do narrador de OESJC, pois atendem de maneira específica aos interesses desse artigo, principalmente no que se refere ao foco narrativo.

Podemos classificar o narrador evangelista como um narrador heterodiegético de focalização onisciente.

A complexidade do narrador saramaguiano não está apenas na sua focalização, mas também na localização temporal do mesmo. Localiza-lo na narrativa é ponto crucial para a interpretação da obra, uma vez que seus comentários críticos podem ser destinados aos comportamentos do tempo de Jesus, mas também ao leitor contemporâneo.

A descrição, nas primeiras páginas do livro retrata uma cena que é a crucificação de Cristo. O modo como a narração é feita sugere que o narrador está descrevendo uma figura: “O que temos diante de nós é papel e tinta e mais nada” (SARAMAGO, 1991, p. 7). Há outros indícios de que o narrador nessa primeira parte é um espectador descrevendo um quadro, ou uma gravura, como mais tarde o próprio Saramago irá confirmar.

Os indícios são expressões que localizam as formas descritas no espaço: [...] "canto superior [...] à esquerda” (p. 7), “em plano próximo” (p. 8), "lugar central” (p. 9), “no chão” (p.11), “ao fundo”, “cá mais perto”, “lá atrás” (p.13). Esses dêiticos descrevem um texto imagético, que mostra a crucificação de Cristo. A história, portanto começa contando seu fim, ainda que de maneira distinta de como será narrada no final d'OESJC. Tudo isso reforça a ideia de um narrador que está anos a frente do tempo em que se passa a vida de Jesus.

Há outros indícios de que o narrador localiza-se a pelo menos dois mil anos a frente do que é narrado. Apesar de muitas vezes a narração ser feita no presente a leitura da obra indica que esse narrador onisciente está no futuro:

Talvez por não se encontrar igualmente desperto em cada um dos seus cinco sentidos, se é que, então, nesta época de que vimos falando, não estavam as pessoas ainda a aprender alguns deles [...] (SARAMAGO, 1991, p. 22) [...] não valia a pena andar à procura de casa, tanto mais que o problema de habitação já era naquela época uma dor de cabeça, com a agravante de não estar ainda inventado o benefício social e usurário do aluguer de quartos (SARAMAGO, 1991, p. 88)

Quem o quiser ver, hoje, não tem mais do que ir à paróquia de Calcata, que está perto de Viterbo, cidade italiana [...] (SARAMAGO, 1991, p. 89). [...] sem um santo alpinista para ajudar [...] (SARAMAGO, 1991, p.91). 
A um espírito voltaireano, irônico e irrespeitoso, se bem que nada original. (SARAMAGO, 1991, p. 98)

[...] e outro ainda em que, por causa duma auto-estrada, ou duma escola, ou duma casa de morar, ou dum centro comercial, ou dum fortim de guerra, as escavadoras revolverão o terreno e farão sair à luz do dia, assim outra vez nascidos, os esqueletos que por dois mil anos ali jazeram. Virão então os antropólogos e um professor de anatomia examinará os restos, para mais tarde anunciar ao mundo escandalizado que, naquele tempo, os homens, afinal, eram crucificados com as pernas encolhidas [...] (SARAMAGO, 1991, p. 176)

[...] imaginar sentimentos modernos e complexos na cabeça de um aldeão palestino nascido tantos anos antes de Freud, Jung, Groddeck e Lacan terem vindo ao mundo [...] (SARAMAGO, 1991, p. 200)

[...] basta ver que o próprio Golias só não foi para jogador de futebol por ter nascido antes do tempo [...] (SARAMAGO, 1991, p. 225)

[...] e caiu velozmente como o machado das execuções ou a guilhotina que ainda falta inventar. (SARAMAGO, 1991, p. 264)

Todos esses trechos confirmam que o narrador apesar de narrar fatos da vida de Jesus como se estivesse no presente, é uma voz que conhece o futuro e, portanto, podemos estender que a sua crítica também se volta para o tempo futuro, para a sociedade contemporânea.

A voz narrativa não está localizada em um tempo definido, mas viaja no tempo e na narrativa com naturalidade, o que confirma seu total controle sobre o que narra.

Um narrador que tem conhecimento do passado do presente e do futuro das personagens. Quando faz críticas à atitude desses personagens também está criticando o tempo contemporâneo. Ele faz questão de avisar o leitor que não é uma voz do tempo de Jesus, e que, portanto, conhece a sociedade e os costumes do presente do leitor.

Colocadas essas questões sobre as características da voz narrativa, começaremos nossa análise pelo título da obra, uma instância que não está ligada diretamente ao narrador, porém dá pistas da estrutura narrativa que o leitor irá se deparar ao ler o romance.

Podemos considerar o título O Evangelho Segundo Jesus Cristo como uma estratégia textual que forma, juntamente com a epígrafe o que chamamos paratexto, ou seja, não compõem a narrativa propriamente dita, mas introduzem o texto. São estratégias ligadas ao que descrevemos anteriormente como autor modelo, mas que preparam o leitor para a narração:

O texto literário recorre muitas vezes a elementos de caráter paratextual [...] como forma de integrar num contexto cultural em que pode constituir-se como obra literária. Um desses elementos é o título, sintagma de identificação do texto, normalmente de curta extensão e desempenhando funções primordialmente semântico-pragmáticas. (REIS, 1995, p. 213) 
Segundo Carlos Reis, o título tem como uma de suas funções chamar a atenção do leitor. Essa instância paratextual será o primeiro contato do leitor com a obra e, portanto, a partir dele algumas possibilidades de interpretação podem ser formuladas.

Escolhemos tratar do título porque a primeira ideia que o leitor de OESJC tem é de que o narrador da obra será o próprio Jesus, uma vez que o título parece sugerir isso.

Ao colocar no título a palavra segundo o leitor pode remeter aos Evangelhos do Novo Testamento: Evangelho Segundo Mateus, Evangelho Segundo Marcos, Evangelho Segundo Lucas e Evangelho Segundo João. Todavia não é Jesus que irá narrar à história de sua vida na obra escrita por Saramago, mas sim um narrador responsável por relatar a sua visão da história de Cristo.

A leitura do livro mostrará que Jesus é o personagem principal dessa história, porém não é o narrador. E nesse ponto será útil a teoria e a classificação de Genette, explorada no início desse artigo: O evangelho não é narrado segundo Jesus, no sentido de por Jesus, mas sim segundo uma nova visão de sua vida.

Essa nova visão da vida de Jesus é o foco narrativo do narrador desse Evangelho, que não é o protagonista, nem é personagem da narrativa, é heterodiegético, segundo a classificação de Genette. Ele possui todo o conhecimento sobre a vida das personagens e seus pensamentos, é um narrador que tem alcance ilimitado dos fatos, e do tempo, já que cita acontecimentos futuros e conversa com o leitor sobre questões que ultrapassam questões ligadas a vida de Jesus. Ele desempenha o papel de narrar e descrever tudo e todos, no entanto, tem o poder de fazer essa narração da maneira que lhe convém, já que o ponto de vista da sua focalização é onisciente.

Para Tereza Cristina Cerdeira da Silva "segundo não sinaliza autoria, mas tão somente ótica narrativa” (SILVA, 1999, p.51). E será essa ótica narrativa que conduzirá o leitor pela história de Cristo, a partir dessa nova versão criada por um narrador que escolhe para onde irá apontar seu foco é que iremos traçar um perfil de humanidade.

Todavia, antes de nos atermos ao modo de narrar dessa figura onisciente que conduz o leitor pelo Evangelho saramaguiano, comentaremos outra estratégia textual, as epígrafes. Seguindo a estrutura linear do livro, após o título o leitor depara-se com duas epígrafes em OESJC que também não estão ligadas ao narrador, mas que ajudam a entender melhor a instância narrativa.

A primeira epígrafe é o prólogo do Evangelho Segundo Lucas:

Já que muitos empreenderam compor uma narração dos factos que entre nós se consumaram, como no-los transmitiram os que desde o princípio foram testemunhas oculares e se tornaram servidores das Palavras, resolvi 
eu também, depois de tudo ter investigado cuidadosamente desde a origem, expor-tos por escrito e pela sua ordem, ilustre Teófilo, a fim de que reconheça a solidez da doutrina em que foste instruído.(LUCAS, 1, 1-4)

O prólogo tirado de um dos evangelhos canônicos pode ser interpretado como uma estratégia, já que estamos diante de uma obra paródica. Ao utilizar um trecho do livro parodiado o autor introduz seu leitor em um ambiente de ironias e metalinguagem que criará sua intenção: recontar a história de Jesus sob um novo foco, uma nova versão dos fatos.

A escolha dessa epígrafe atende as perfeitamente as intenções d' OESJC e de seu narrador, assim como Lucas, o narrador saramaguiano também irá contar a história de Jesus, mesmo "que muitos empreenderam compor (essa) narração”. Outro fato curioso é que Lucas, segundo consta na Introdução particular aos livros do Novo Testamento, da Bíblia traduzida pelo Centro bíblico católico:

(Lucas) é também um companheiro das missões de Paulo, aquele mesmo que escreveu aos Atos dos Apóstolos pouco antes de 68. Seu Evangelho é, pois, anterior a esta data, embora não tenha ele sido testemunha ocular dos acontecimentos, seu livro é digno de crédito por causa do cuidado que teve o autor de documentá-lo. Ele utilizou certamente o texto de Marcos e de Mateus. (BÍBLIA SAGRADA, 1998)

Esse comentário sobre Lucas reforça a possível intenção do autor em criar uma paródia que se sustenta nas lacunas do texto parodiado e levanta questões que ultrapassam a simples ridicularização do texto bíblico. Lucas não foi testemunha ocular da vida de Jesus, no entanto também se compromete a escrever sua versão dos fatos, e para isso utiliza os textos de Marcos e Mateus, tal qual o autor modelo saramaguiano, a história foi recontada.

No entanto, quando nos referimos ao texto de Saramago estamos diante de uma obra de ficção que não tem pretensões de ser verdade absoluta, mas que brinca com esse fato. Quando olhamos sob o prisma da paródia que está presente em todo o livro, a última frase da epígrafe "a fim de que reconheças a solidez da doutrina em que foste instruído” torna-se uma grande ironia, porque se é possível, que cada autor conte sua versão dos fatos, a doutrina talvez não seja tão sólida assim. E ainda, essa citação de no Evangelho de Lucas refere-se àquilo que a Igreja aceita como dogma, enquanto, na obra de Saramago, podemos interpretar que só agora, com a leitura do seu livro, vai-se conhecer a verdade dessa história secular.

A segunda epígrafe, que está em latim: “Quod scripsi, scripsi.”, que significa "O que escrevi, escrevi.”, funciona como um possível resposta a quem questionar a versão da vida de Cristo apresentada no romance. Essa frase também foi retirada da Bíblia e se encontra no Evangelho de João: 
Pilatos redigiu também uma inscrição e afixou em cima da cruz. Nela estava escrito: "Jesus de Nazaré, rei dos judeus”. Muitos dos judeus leram esta inscrição, porque Jesus foi crucificado perto da cidade e a inscrição era redigida em hebraico, em latim e em grego. Os sumos sacerdotes dos judeus disseram a Pilatos: "Não escrevas: Rei dos judeus, mas sim: Este homem disse ser o rei dos judeus”. Respondeu Pilatos: O que escrevi, escrevi. (JOÃO 19: 19-22)

Novamente o autor utiliza o texto parodiado para atender as suas intenções, com essa frase de Pilatos a resposta a quem questionar sua versão já foi dada. Está escrito e não será mudado. Com a leitura do romance, tomamos conhecimento que Jesus causará a ira dos romanos quando começar a dizer que é Rei dos judeus, e não por se dizer Filho de Deus. A questão política, mundana, terrena é que incomoda de fato os inimigos de Jesus e o contexto da epígrafe já aponta para isso.

A subversão da vida de Jesus tem início desde o título e se estende para as epígrafes que não são instancias do narrador, mas que já preparam o leitor para o foco narrativo que esse romance irá trabalhar: contar episódios da vida de Jesus que são polêmicos e cheios de lacunas.

Seguindo a linearidade do livro o primeiro parágrafo do primeiro capítulo começa com a descrição de uma crucificação, que é apresentada ao leitor aos poucos e termina com a afirmação "o que temos diante de nós é papel e tinta, mais nada” (SARAMAGO, 1991, p. 7), e depois de uma longa descrição da crucificação é que se inicia o capítulo que conta a noite que Jesus foi concebido.

Teremos como guia de leitura um narrador que questiona o mundo e também a própria literatura. E mais, com as constantes ironias aos poderosos, há uma preferência pelos menos favorecidos, já que ridiculariza personagens que ocupam alguma posição de poder.

Esse narrador não esconde sua onisciência, sabe tudo sobre Jesus, Maria, José, Deus e o Diabo e até mais do que eles. Sua onisciência é plena e ele anuncia isso por várias vezes durante o texto através da metalinguagem ou interpolações auto reflexivas:

O narrador do ESJC é um narrador que poderia ser denominado, segundo algumas linhas teóricas, como: extradiegético (Genette), porque narra uma história da qual não participa, possuindo o que se chama focalização zero e atuando como um soberbo demiurgo, plenamente onisciente; seria dotado de uma “visão por trás” (FERRAZ, 2012, p. 154)

Sendo um narrador com a onisciência ilimitada, ele escolhe o que narrar e como narrar à vida de Jesus, quais pontos são convenientes para retratar a imagem humana de Jesus, a imagem forte de Madalena, a imagem frágil e desprezível de Herodes e a imagem de fraqueza de Maria e José: 
[...] o narrador utiliza a intrusão para passar direta e explicitamente a sua concepção de mundo ao leitor [...], ao lado de outras concepções expressadas pelas personagens, representam verdadeiras posições filosóficas e questionamentos profundos sobre o machismo, a eterna culpa que passa de pai para filho, o destino, o maniqueísmo, mas principalmente o caráter de Deus. (FERRAZ, 2012, p. 159)

E é exatamente essa visão de mundo que Salma Ferraz destaca na citação acima. Apenas para exemplificar a onisciência e a maneira como o narrador manipula as informações durante a narrativa, citaremos trechos nos quais o narrador opta por esconder do leitor algumas informações, reforçando sua posição demiúrgica, ou seja, é o criador absoluto da narrativa e distribui os fatos como quer:

[...] Simeão pôs a mão direita sobre a cabeça de José, murmurou uma benção que ninguém pode ouvir e foi-se juntar-se aos seus [...] (SARAMAGO, 1991, p.69)

[...] até que consiga pronunciar a primeira palavra, qual ela tenha sido não sabemos, talvez papa, talvez papá, talvez mamã [...] (SARAMAGO, 1991, p. 128)

Murmurou Tiago palavras que não se ouviram, mas que deviam ter sido um comentário ácido sobre aqueles que presumem de saber de tudo. (SARAMAGO, 1991, p. 296)

Mesmo que as informações omitidas ao leitor sejam irrelevantes para o desenvolvimento da narrativa, essa estratégia, além de aproximar o narrador do leitor, porque envolve essas entidades em uma espécie de cumplicidade (nós não sabemos), é extremamente irônica, uma vez que o narrador sabe absolutamente tudo sobre a narrativa, ele apenas opta por não contar alguns detalhes, criando um jogo no qual envolve seu leitor.

Se levarmos isso em consideração, a última citação torna-se extremamente significativa e um exemplo claro das estratégias do narrador: "mas que deviam ter sido um comentário ácido sobre aqueles que presumem de saber de tudo.” (SARAMAGO, 1991, p. 296). O narrador não faz apenas uma crítica a quem presume saber tudo, mas também a ele mesmo, uma vez que, desde o início da obra, se coloca como alguém que conhece todos os detalhes da narrativa:

Só um habitante doutro planeta, suponho que nele não houvesse repetido alguma vez, ou mesmo estreado, este drama, só esse em verdade inimaginável ser ignoraria que a afligida mulher é a viúva de um carpinteiro chamado José. (SARAMAGO, 1991, p. 9)

Afinal uma história arquiconhecida mas ao narrador deste evangelho não parece que seja a mesma coisa, tanto no que toca ao passado como no que ao futuro há-de tocar...” (SARAMAGO, 1991, p.127). 
Nós, pelo contrário, conhecemos tudo quanto até hoje foi feito, dito e pensado, quer por eles quer pelos outros [...] (SARAMAGO, 1991, p. 206)

[...] nós, sim, que, como Deus, tudo sabemos [...] (SARAMAGO, 1991, p. 239)

Esses trechos não apenas confirmam a consciência de onipresença do narrador, como nos ajuda a perceber suas estratégias para se aproximar do leitor, usando a primeira pessoa do plural (nós), por exemplo.

Não podemos falar de Saramago e especificamente d'OESJC, sem falar de questões como ironia e paródia. Esses dois conceitos são importantes para atingir o objetivo desse artigo, que é traçar o perfil do narrador.

É preciso deixar claro, que a estamos tratando OESJC como um texto paródico e a ironia como uma estratégia retórica utilizada pelo narrador, portanto, abordaremos o tema da paródia em um primeiro momento e depois iremos explorar o conceito de ironia, que servirão como base teórica para nossa análise do olhar do narrador.

OESJC trava um diálogo não apenas com o texto bíblico, mas com a tradição cristã de um modo geral e com a católica de maneira específica. Existe uma grande subversão que se constrói ao longo do romance, e não há dúvida de que temos uma paródia sobre o Novo Testamento:

Os dados históricos de que serve são submetidos a uma interessante modelização paródica, a partir da qual é possível descortinar a ideologia de quem escreve. Isto é, o uso, da imitação que faz da informação histórica oficial traduz-se, na sua essência, num aproveitamento que visa distanciamento crítico. (ARNAUT, 2008, p. 36)

As palavras de Arnaut sobre a ficção de Saramago reforçam a ideia de que a obra do escritor utiliza a paródia como instrumento de crítica, e a partir da qual se pode perceber a visão de mundo de quem escreve. $\mathrm{O}$ distanciamento crítico assinala a diferença entre os textos e esse processo implica uma revisão do texto parodiado (Evangelhos canônicos). Essa revisão não tem o intuito apenas de escarnecer o texto que lhe serve de base, mas também de lançar um olhar crítico aos próprios costumes presentes.

Segundo Linda Hutcheon (1984) há parodias distintas. Algumas se servem do texto parodiado como alvo, enquanto outras se servem dele como arma, a última é o Hutcheon chama de paródia moderna, que iremos usar para classificar OESJC nesse trabalho.

A crítica canadense tem consciência de que os ecos paródicos não são exclusivos do século XX, porém, o grande número de obras que se constitui a partir dessa construção formal, nos mais diversos meios artísticos, sinaliza a importância adquirida pela paródia a partir desse século. $\mathrm{O}$ estudo compreende que a paródia é a repetição com diferença, um modelo complexo de "transcontextualização", inversão e revisão crítica que remete à arte moderna a sua tradição: 
Paródia é, pois, repetição, mas repetição que inclui diferença (Deleuze 1968); é imitação com distância crítica, cuja ironia pode beneficiar e prejudicar ao mesmo tempo. Versões irônicas de "transcontextualização” e inversão são os seus principais operadores formais, e o âmbito de ethos pragmático vão do ridículo desdenhoso à homenagem referencial. (HUTCHEON, 1984, p.54)

Segundo Hutcheon, esse recurso ultrapassa a ideia antiga de paródia como texto "menor”, ou "parasitário", que tinha o intuito de fazer blague de outro texto. A paródia moderna se constitui em um texto que dialoga com outro, e que devido a esse diálogo cria um novo texto, que não tem necessariamente o intuito de ridicularizar, mas de criticar sua própria época.

Se tratarmos a paródia como uma relação entre textos, ou seja, entre o texto parodiado (a Bíblia) e o texto parodístico (OESJC), o passado não é visto de forma nostálgica, mas sim de forma crítica e revisada.

Ao tratar a paródia como algo "muito para além da mera comédia ridicularizadora (HUTCHEON, 1984, p. 37.)” ampliamos a simples ideia de um autor ateu, blasfemando contra um texto religioso: “quando falamos de paródia não nos referimos apenas a dois textos que se inter-relacionam de certa maneira. Implicamos também uma intenção de parodiar outra obra (ou conjunto de convenções) e tanto um reconhecimento dessa intenção. (HUTCHEON, 1984, p.34)”, ou seja, há uma intenção na paródia, que ultrapassa a simples ideia da sátira a um texto anterior.

A paródia, segundo Hutcheon, opera como um método de inscrever a continuidade, permitindo uma distância crítica. Pode funcionar como força conservadora ao reter e escarnecer, simultaneamente, de outras formas estáticas; mas também é capaz de poder transformador, ao criar novas sínteses.

O uso desse recurso nas narrativas recai sobre as subversões realizadas em relação às convenções da forma parodiada e a abordagem criativa que se faz da tradição e que permite o estabelecimento das diferenças a partir do paralelismo. Desse modo, a paródia não se constitui de imitação nostálgica de modelos passados, mas de um fenômeno que envolve a recontextualização de modelos e a consequente alteração dos sentidos. E mais, para Hutcheon "a paródia é uma forma de auto-referencialidade, mas isso não quer dizer que não possua implicações ideológicas (Hutcheon, p. 41)”, ou seja, a paródia, ainda que tenha relação direta com o texto e com os elementos concretos que o compõe, não elimina uma relação externa entre o texto original (parodiado), o texto parodístico e as intenções implícitas em fazer a paródia.

Dessa maneira, o autor, ao recontar histórias conhecidas pelo imaginário popular cristão ocidental, cria um novo texto, que não apenas critica os costumes e crenças do passado, mas que propõe outra visão sobre esses temas, e ao mesmo tempo, faz uma crítica ao tempo presente, imbuído de sua própria visão de mundo. Muitas paródias atuais não ridicularizam os 
textos que lhes servem de fundo, mas utilizam-nos como padrões por meio dos quais colocam o contemporâneo sob análise.

Hutcheon chama atenção para outro ponto importante que é o papel do leitor na paródia moderna. A crítica levanta a questão, que em alguns romances modernos (no qual incluímos OESJC), o leitor é nitidamente dirigido, “instruído até”, pela voz narrativa e também pelas estruturas paródicas em si:

Aqui a paródia tem aquilo a que poderíamos até chamar uma função ideológica, pois semelhante retratamento das convenções do passado funciona de modo a dirigir o leitor para preocupações morais e sociais do romance [...] É nesse ponto que a paródia adquire dimensões que ultrapassam os limites literários do texto, tornando-se uma metáfora para contextos mais amplos: aos leitores desse romance nunca é permitido abster-se de reconhecerem a paródia ou de se julgarem e questionarem a si mesmos. São obrigados a relacionar o passado com o presente - ao nível social e moral bem como literário. (HUTCHEON, 1984, p. 116 - 117)

Para Hutcheon, a paródia atual trabalha deliberadamente para orientar ou desorientar o leitor. Para a autora há inúmeras maneiras de fazer isso “da agressão à sedução”. O leitor participa da geração de sentido, no entanto isso não é garantia de liberdade. Há narradores manipuladores que usam uma cuidadosa dissimulação para que o leitor se sinta no controle da situação.

Esse é sem dúvida, o caso do narrador de OESJC, sua sedução se manifesta de várias maneiras ao longo do livro O narrador é dotado de estratégias para manipular o leitor e para que esse compartilhe com ele a sua visão sobre a história e sobre os personagens. Dentre todas as artimanhas do narrador saramaguiano a ironia parece a mais forte de suas peculiaridades:

[...] é impossível evitar a tentação de citar o escritor José Saramago, que elaborando romances altamente irônicos, [...] não deixa de usar as mencionadas expressões, na condição de narrador empenhado em estabelecer a cumplicidade com o leitor e deixar muito clara sua posição crítica e saborosamente humorada. (BRAIT, 1996, p.22)

Essa citação de Beth Brait, nos ajuda a perceber que o narrador tem uma intenção inegável de interagir com o leitor e envolve-lo na sua narração. É esse ponto de vista sobre a narração, ou o olhar irônico que o narrador lança sobre os personagens que faz o leitor perceber a visão de mundo presente no texto.

É importante lembrar que quando falamos de ironia é sempre um problema complicado, pois é necessário que o leitor entenda a ironia, se não ela não acontece de maneira satisfatória:

Para ser percebida pelo leitor, a ironia requer certa atenção, além da habilidade de comtemplar ideias opostas, conflitantes. Uma vez destituída de ironia, a leitura perde, a um só tempo, o propósito e a capacidade de sur- 
preender. Se buscarmos, na leitura, algo que nos diz respeito e que pode ser por nós usado para refletir e avaliar, constataremos que esse algo, provavelmente, terá um conteúdo irônico [...] A ironia liberta a mente da presunção dos ideólogos e faz brilhar a chama do intelecto. (BLOOM, 2001, p. 23-24)

As palavras de Bloom reforçam nosso objetivo, que é exatamente compreender de que maneira o olhar irônico do narrador manipula o leitor, para que ele “enxergue” exatamente aquilo que o foco narrativo está destacando.

Essa estratégia textual é tão importante para o estudo d’ OESJC que o próprio narrador usa conscientemente a ironia e até alerta para quando os personagens fazem o uso dessa figura de linguagem:

Esses infelizes, com perdão da triste ironia, ainda tinham sorte sendo crucificados, por assim dizer à porta de casa [...] (SARAMAGO, 1991, p.153) [...] o que levou o Pastor a comentar irônico, este ano não comes o cordeiro pascal (SARAMAGO, 1991, p. 258)

[...] quem te fez pastor perdeu-te, palavras estas simples, de simpática ironia [...] (SARAMAGO, 1991, p. 299)

[...] quem sabe, então, se não foi o Senhor, quem te pôs o dinheiro no alforge, e sorrio quando disse, ironicamente. (SARAMAGO, 1991, p. 300 $-301)$

Uma proposta, tu, e que proposta vem a ser essa, o tom era irônico, superior, capaz de reduzir ao silêncio qualquer que não fosse o Diabo, conhecido e familiar de longa data. (SARAMAGO, 1991, p. 391)

Os trechos nos quais a ironia está presente no evangelho saramaguiano são inúmeros, no entanto os exemplos acima já ajudam a entender a maneira como o narrador se manifesta. No entanto, o trabalho mais difícil do leitor está em decodificar os trechos irônicos que não são explícitos.

Outro ponto que dificulta a decodificação das intenções parodísticas e que precisamos deixar claro é que a ironia não tem necessariamente que ser engraçada:

Conforme Umberto Eco disse a respeito de sua própria metaficção historiográfica e de sua teorização semiótica, o "jogo da ironia” esta intrinsicamente envolvido na seriedade do objeto e do tema. Na verdade, talvez a ironia seja a única forma de podermos ser sérios nos dias de hoje. Em nosso mundo não há inocência, ele dá a entender. Não podemos deixar de perceber os discursos que precedem e contextualizam tudo aquilo que dizemos e fazemos, e é por meio da paródia irônica que indicamos nossa percepção sobre esse fato inevitável. Aquilo que já foi dito precisa ser reconsiderado, e só pode ser reconsiderado de forma irônica. (HUTCHEON, 1984, p. 62)

Usando Eco como exemplo, Hutcheon esclarece que a paródia moderna que utiliza a ironia como seu principal recurso linguístico é a forma de arte mais utilizada no século XX para revisitar o passado e entender o presente. 
Esse tipo de arte necessita um leitor ativo, que perceba as intenções do texto e que compartilhe com o autor de algumas convenções ou a ironia não é percebida, e na mais radical das possibilidades a paródia não é lida como paródia.

Brait também chama atenção para esse fato, a autora cita Sigmund Freud o psicanalista alemão, que atento ao assunto da ironia tenta explicar a figura em questão: “a única técnica que caracteriza a ironia é a representação pelo contrário” (FREUD apud BRAIT, 1996, p. 44).

Para Freud, a ironia, para ser completa, deveria vir acompanhada de alguns indícios de sua intenção, como insinuações, tom de voz, contexto, ou mesmo um sorriso como escreveu Saramago em outro romance seu: "vejamos como ficou Ricardo Reis a sorrir ironicamente, é um jeito de lábios que não engana, quando quem inventou a ironia inventou a ironia, teve também de inventar o sorriso que lhe declarasse a intenção, alcançamento muito mais trabalhoso” (SARAMAGO, 1988, p.48).

A paródia saramaguiana se constrói através da voz de um narrador onisciente, autoritário, demiurgo, e acima de tudo irônico, que, ao lançar seus comentários, ou esconder algumas questões do leitor, envolve e seduz. O leitor, no entanto precisa participar de forma ativa da obra, para decodificar as intenções paródicas do narrador. O jogo narrativo se completa e é possível perceber de que maneira o narrador induz seus leitores a compartilhar com ele as mesmas questões morais, sociais, políticas e éticas que compõem o livro.

\section{Referências}

ADAM, Jean-Michel; REVAZ, Françoise. A análise da narrativa. Lisboa: Gradiva,

1997.

BARTHES, Roland. O rumor da língua. São Paulo: Brasilienses, 1988.

BÍBLIA DE JERUSALÉM. São Paulo: Paulus, 2008.

BLOOM, Harold. Como e por que ler. Rio de Janeiro: Objetiva, 2001.

BRAIT, Beth. Ironia em perspectiva polifônica, Campinas: Editora Unicamp, 1996.

DAL FARRA, Maria Lúcia. O narrador ensimesmado. São Paulo: Ática, 1978.

FERRAZ, Salma. As faces de Deus na obra de um ateu. José Saramago - 2. ed. rev. e ampl. - Blumenau: Edifurb, 2012.

GANCHO, Cândida Vilares. Como analisar narrativas. São Paulo: Ática, 1995. 
GENETTE, Gérard. Discurso da narrativa. Lisboa: Vega, 1980.

. “Fronteiras da narrativa”. In: Análise estrutural da narrativa.

Petrópolis: Vozes, 1971.

HUTCHEON, Linda. Uma teoria da paródia: ensinamentos das formas de arte do século XX. Trad. de Tereza Louro Pérez. Lisboa: 1984.

REIS, Carlos. Estatuto e perspectivas do narrador na ficção de Eça de Queirós. Coimbra: Almedina, 1975.

SARAMAGO, José. Entrevista de José Saramago a José Carlos Vasconcelos. In: Revista Visão, Lisboa, 2003.

. Entrevista de José Saramago a Horácio Costa. In: Revista

Cult. Disponível em: <http://revistacult.uol.com.br/home/2014/10/ saramago-o-despertar-da-palavra/ >

das Letras, 2010.

. O Evangelho Segundo Jesus Cristo. São Paulo: Companhia . O ano da morte de Ricardo Reis. Lisboa: Caminho, 1984.

SEIXO, Maria Alzira. Lugares da ficção em José Saramago. Lisboa: INCM, 1999.

SILVA, Tereza Cristina Cerdeira da. José Saramago entre a história e a ficção: uma saga de portugueses. Lisboa: Dom Quixote, 1989.

O quinto evangelista ou a tigela do Graal. In: Anais do XIV Encontro de Professores Universitários Brasileiros de Literatura Portuguesa. Porto Alegre, EDIPUCRS, Agosto/1992.

Recebido em novembro/2015

Aceito em dezembro/2015 